\title{
ElECTRONIC DEVICE TO IMPROVE THE EFFICIENCY OF EXTRACORPOREAL LITHOTRIPTERS
}

\author{
F. Fernández', A. M. Loske', J. van Cauwelaert', F. E. Prieto² \\ ${ }^{1}$ Centro de Física Aplicada y Tecnología Avanzada, UNAM, \\ Apdo. Postal 1-1010, C.P. 76000 Querétaro, Qro., México, \\ Tel. (52) (442) 2381164, Fax: (52) (442) 2381165, \\ fcofdez@servidor.unam.mx, loske@fata.unam.mx \\ ${ }^{2}$ Instituto de Física, UNAM, Apdo. Postal 20-364, \\ C.P. 01000, México, D.F., Tel. (52) (55) 562334164, \\ Fax. (52) (55) 56234165, loske@fisica.unam.mx
}

Received: January $8^{\text {th }} 2003$ and accepted April $30^{\text {th }} 2003$

\begin{abstract}
The design and construction of autonomous electronic instrumentation to generate fast high voltage discharges (6 to $10 \mathrm{kV}$ ) on a piezoelectric crystal array, in order to produce underwater shock waves, is described. If properly focused, hundreds of these shock waves are capable of destroying renal and ureteral calculi. This clinical treatment, developed more than 20 years ago, is known as extracorporeal shock wave lithotripsy (ESWL). In contrast to standard devices, our system produces two, rather than just one, shock waves with an adjustable delay between 50 and $950 \mu \mathrm{sec}$. The objective is to enhance cavitation-induced damage to the kidney stone without increasing tissue trauma. Kidney-stone model fragmentation tests, obtained with the novel system, were compared to those achieved with a conventional piezoelectric shock wave generator, showing a $20 \%$ increase in fragmentation efficiency. Initial in vivo studies with animals have shown reduced tissue trauma.
\end{abstract}

\section{RESUMEN}

Se presenta el diseño y la construcción de instrumentación electrónica autónoma que permite generar descargas abruptas de alto voltaje ( 6 a $10 \mathrm{kV}$ ) sobre arreglos de cristales piezoeléctricos, para provocar ondas de choque en agua. Debidamente enfocadas, estas ondas son capaces de destruir cálculos renales y uretrales, según la técnica médica no invasiva conocida como litotripsia extracorporal. La innovación en este sistema, comparada con la forma convencional de descargas sucesivas espaciadas durante el orden de segundos, consiste en generar dos impulsos con retardo variable y controlado entre 50 y 950 microsegundos, repitiendo sucesivamente el proceso con período también variable y controlado entre 1 y 10 segundos, en lo que se pretende aprovechar el fenómeno de cavitación para mejorar la eficiencia en la desintegración de cálculos, sin incrementar el daño a los tejidos.

Las pruebas efectuadas con modelos artificiales de cálculos renales, muestran un aumento aproximado del 20\% en la eficiencia del generador de ondas de choque, con respecto a la manera convencional. Estudios recientes in vivo (con animales) han demostrado una reducción significativa en el daño a los tejidos circundantes al cálculo.

KEYWORDS: Piezoelectric shock wave generation, Tandem shock waves, Cavitation, ESWL. 


\section{INTRODUCTION}

Extracorporeal shock wave lithotripsy (ESWL) has been used successfully for more than two decades to treat patients having ureteral, renal, and sometimes even gallbladder, pancreatic and salivary stones [1]. The goal of ESWL is to provide efficient calculi fragmentation with the least amount of tissue trauma. Even if ESWL is believed to be a safe and reliable treatment, techniques and clinical devices (called lithotripters) are still evolving and new systems to reduce tissue damage and increase stone fragmentation efficiency are constantly sought.

Basically, three different methods are used to generate shock waves for clinical applications: electrohydraulic, electromagnetic and piezoelectric [2,3]. This article is only dealing with piezoelectric shock wave generation; however, the basic physical principles described here could also be used in electrohydraulic and electromagnetic lithotripters.

Shock waves are generated in water because its acoustic impedance is similar to that of soft human tissue. Acoustic cavitation is believed to be one of the major mechanisms involved in stone fragmentation during ESWL $[4,5]$. The negative pulse of a lithotripter shock wave normally exceeds the threshold for cavitation in water (or urine) forming a cloud of bubbles in the vicinity of the lithotripter focus. When these bubbles collapse, they produce high-speed liquid microjets, damaging the stone surface. Even if the total energy of a single cavitation event is small, its concentration into a tiny volume may cause an enormous energy density, with large potential for damage. If a second shock wave is sent during bubble collapse, even higher energy densities can be achieved. This has been shown using either two shock wave generators or composite reflectors [6,7]. The disadvantage of these systems is the need of two independent shock wave generators or a different composite reflector for each time delay between shock waves.

The objective of this article is to report the design of novel electric and electronic circuits for a piezoelectric shock wave generator, in order to enhance cavitation-induced damage to kidney stones without increasing tissue trauma. The system generates two successive shock waves with an adjustable time delay between 50 and $950 \mu$ s, using only one shock wave generator. Pressure measurements and stone fragmentation efficiency of the new system were compared to that of a standard piezoelectric lithotripter.

\section{THE PIEZOELECTRIC SHOCK WAVE GENERATOR}

Standard piezoelectric lithotripters have up to 3000 piezoceramic crystals, arranged on the concave surface of a metallic spherical segment. Crystals are connected in parallel and stimulated by an electric discharge, which is generated with a pulse generator, allowing different levels of pulse intensity. Each electric pulse causes expansion of all the crystals at the same time, producing a pressure wave. A rarefaction or "negative" pressure pulse results when crystals return to their initial shape. Due to of the spherical arrangement, energy is concentrated at the center $(F)$ of the sphere (about $0.25 \mathrm{~m}$ in radius). As illustrated in Fig. 1-a, this is the position where the kidney stone is placed during ESWL. The concave dish with the ceramic elements mounted on it (shock wave generator), is placed inside a cavity filled with degassed water, warmed to body temperature. Piezoelectric crystals are insulated from water by a flexible polymeric material. A latex membrane couples shock waves into the patient. If the patient is positioned with the stone located at the focus $F$, shock waves enter his body, become focused on the calculus, and fracture it (see Fig. 1-b). Patient positioning is performed by ultrasound or fluoroscopy.

For the purpose of this research there was no need for a complete lithotripter; nevertheless, the instrumentation and electric circuits described in this article may be installed in any standard clinical piezoelectric lithotripter. Because of this, only the shock wave generator of a Piezolith 2300 extracorporeal shock wave lithotripter (Richard Wolf GmbH, Knittlingen, Germany) was mounted on a bench. A cylindrical lucite water tank was placed on the piezoelectric shock wave generator (see Fig. 2). The XYZ positioner, placed on top of the tank, was used to position either needle hydrophones (Imotec $\mathrm{GmbH}$, Würselen, Germany) or well known spherical standardized kidney stone phantoms at $F$. 


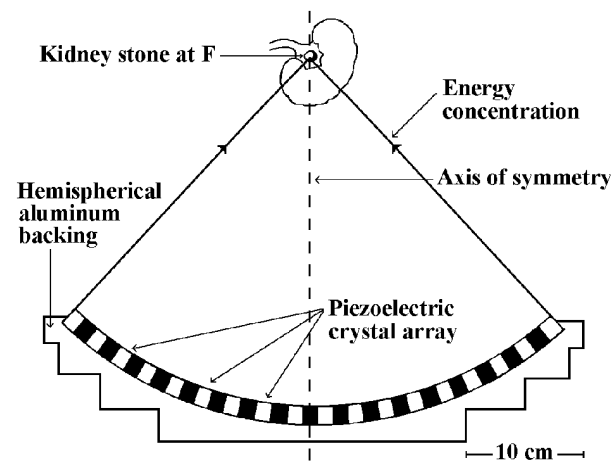

(a) piezoelectric shock wave generator and

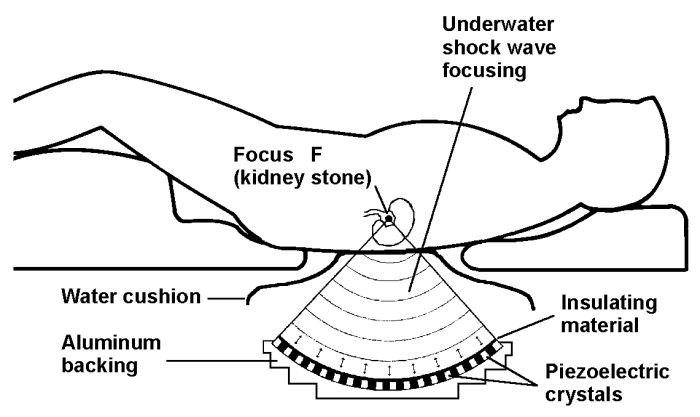

(b) focusing for extracorporeal kidney stone disintegration

Figure 1. Schemes of

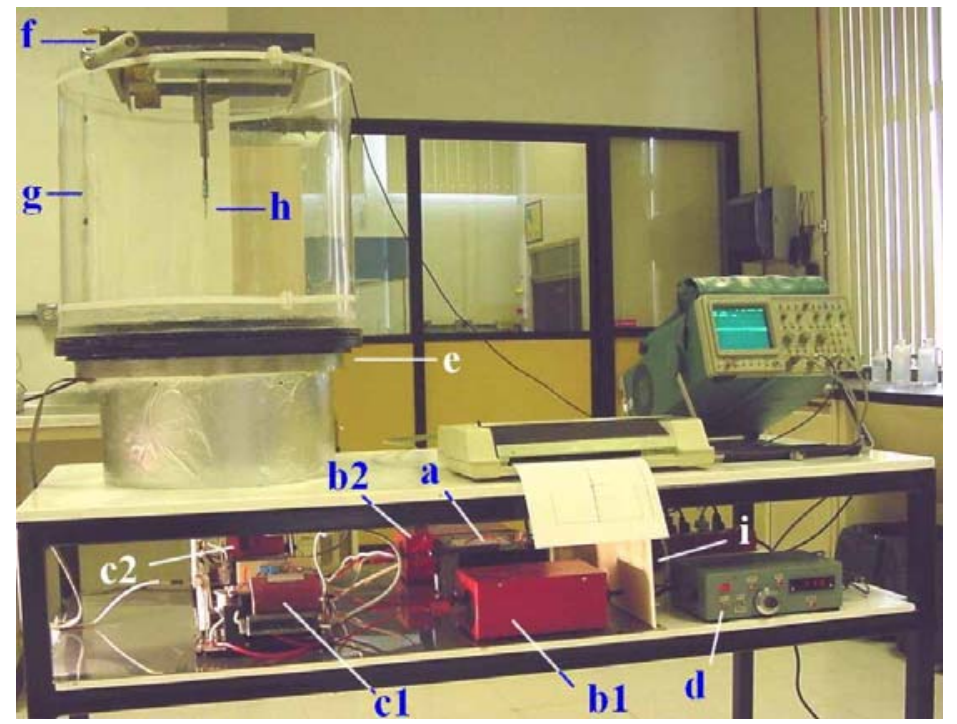

Figure 2. Photograph showing (a) the high voltage transformer, (b1) the spark gap driver 1 , (b2) the spark gap driver 2, (c1) rectifier 1, C1 and spark gap 1, (c2) rectifier 2, C2 and spark gap 2, (d) the pulse generator,

(e) the hemispherical aluminum backing with the piezoelectric crystals, (f) the XYZ positioner, (g) the water tank,

(h) the PVDF needle hydrophone, and (i) part of the shielding 
The electric circuit of the Piezolith 2300 lithotripter, consisting of a capacitor charging system and a spark gap trigger unit, was duplicated and both high voltage outputs connected in parallel to the piezoelectric shock wave generator as shown in Fig. 3. Two spark gap drivers and a specially designed pulse generator can also be seen on this figure.

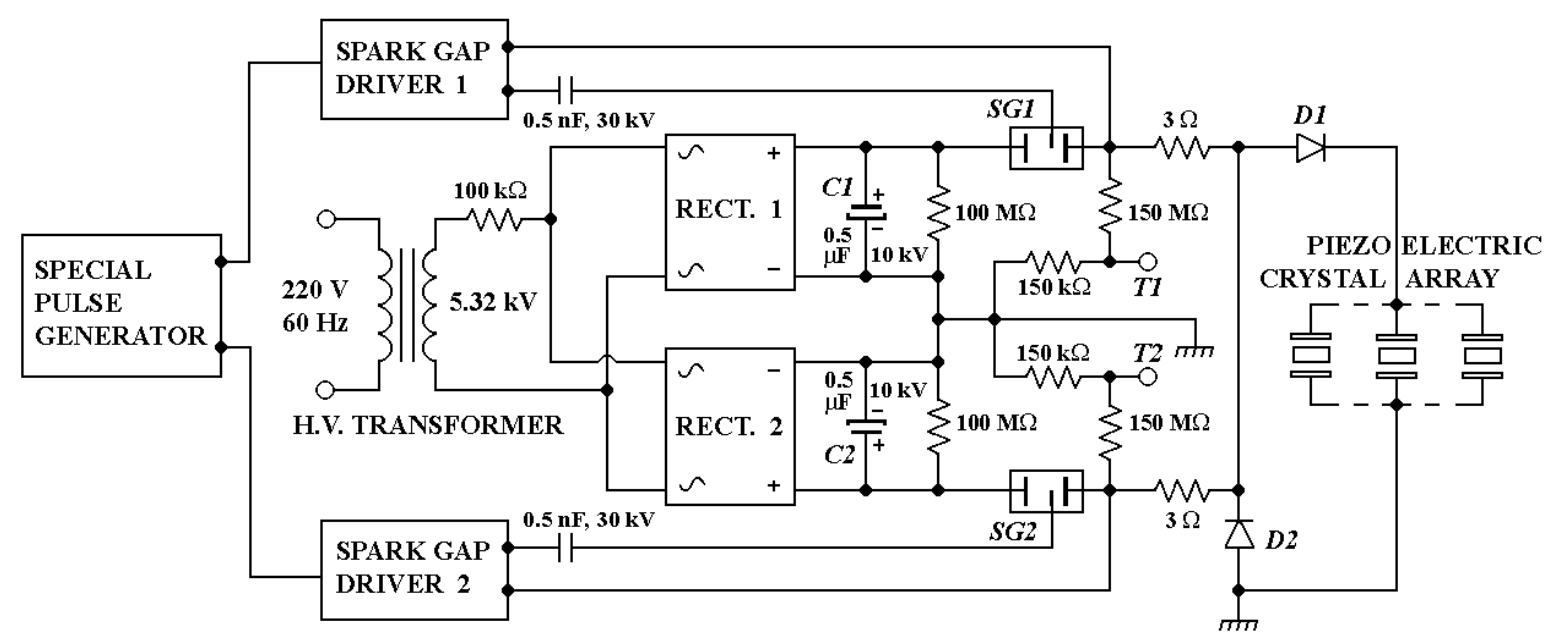

Figure 3. Diagram of the novel circuit

The high voltage transformer (input: $220 \mathrm{~V}_{\text {evs, }} 60 \mathrm{~Hz}$; output: $5.32 \mathrm{kV}_{\text {Rus }}$ ) charges $C 1$ and $C 2$ up to $7.5 \mathrm{kV}$ oc, through a 100 $\mathrm{k} \Omega$ resistor and rectifying bridges 1 and 2 formed with NTE517 (15 kV, $0.55 \mathrm{~A})$ diodes. The $100 \mathrm{k} \Omega$ resistor reduces the surge current to maximum $75 \mathrm{~mA}$, at a $50 \mathrm{~ms}$ charging time constant. Capacitors $C 1$ and $C 2$ maintain $7.5 \mathrm{kV}$ oc until either spark gap $S G 1$ or $S G 2$ is fired. At this instant, the energy stored in one of the capacitors is discharged through a $3 \Omega$ resistor and diode $D 1$, exciting the piezoelectric crystal array. A digital oscilloscope connected to $T 1$ and $T 2$ is used to observe the electric discharges and measure the time delay between them. D1 and D2 prevent undesirable return of positive and negative pulses, due to ringing of the piezoelectric crystal array.

Spark gaps SG1 and SG2 basically consist of two main electrodes (input and output electrode) separated a distance large enough to resist $7.5 \mathrm{kV}$, and a trigger electrode, located next to the output electrode. A high voltage, low current, electric discharge between the trigger and the output electrode ionizes the gas between main electrodes, inducing the high energy discharge. After the first spark gap (SG1) is fired, diode D2 prevents the pulse, generated by the crystals when retracting, to trigger spark gap number two (SG2). Without $D 2$, a negative peak was seen traveling from the piezoelectric crystals to the output of $S G 2$ and the increased voltage difference between input-output electrodes would fire $S G 2$ before arrival of the trigger pulse coming from the pulse generator. This was handled by grounding the negative peak through D2. Positive pulse reflections were prevented by D1. Since the time for the piezoelectric crystals to return to their initial dimensions is less than one microsecond [8], tandem shock wave generation with minimum delay of $10 \mathrm{~s}$ (between 50 and $950 \mathrm{~s}$ ) is possible, by means of the spark gap drivers and the special pulse generator.

Each spark gap driver receives a $50 \mu \mathrm{s} T \mathrm{~L}$ signal and produces a $12 \mathrm{kV}, 3 \mathrm{~mA}, 5 \mu \mathrm{s}$ pulse output, enough to ionize either SG1 or SG2. The pulse generator was designed to trigger both systems with an adjustable time delay between

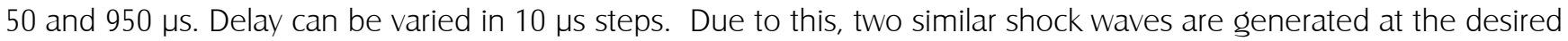
time delay. The system can be operated in manual single-shot tandem shock wave mode, or in automatic tandem mode at an adjustable frequency between 0.1 and $1.0 \mathrm{~Hz}$. A four digit counter registers the number of generated tandem shock waves. More details on the electronics are given in the following section. 


\section{INSTRUMENTATION}

\subsection{The spark gap drivers}

As shown in Fig. 4, each spark gap driver operates with a $12 \mathrm{~V}, 1.2 \mathrm{~A}$-h, independent rechargeable battery unit, in order to have floating output terminals over common ground. The basic arrangement is similar to spark plug discharge circuits used in some combustion engines. A standard automobile coil was used in the Darlington arrangement formed by Q3 and Q4 transistors, whose transition time [9] sets the amplitude and duration of the output high voltage pulse. A SN74121 integrated circuit (IC) in monostable operation supplies a $2.8 \mathrm{~ms}$ TTL pulse [10], controlling transistor Q2 which drives the Darlington setup. The IC is triggered by Q1. To insulate the spark gap driver from the pulse generator, an opto-coupled interrupter module (ECG3100, led-phototransistor) was used to drive Q1 (only the phototransistor is shown in Fig. 4). Diode $D 1$ allows battery recharging with a standard charging unit, not shown in Fig. 4. With full battery charge, the system has 12 hours of autonomy.

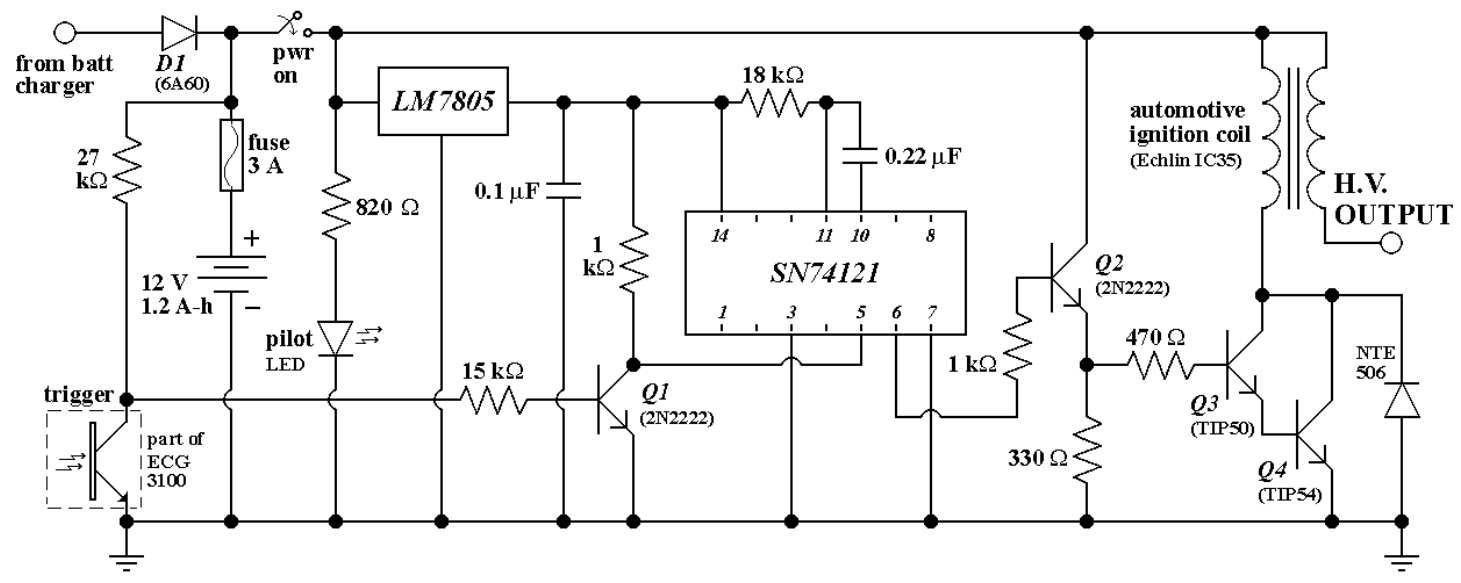

Figure 4. Diagram of the spark gap driver circuits

\subsection{The special pulse generator}

In this stage, our established design specifications were the generation and coupling of the three time-base signals (with TLL levels) mentioned in section 2:

$1^{\text {st: }}$ A variable frequency from 0.1 to $1 \mathrm{~Hz}$, in order to repeat the two succesive shock waves (tandem shock waves) in automatic mode.

$2^{\text {nd: }}$ The 50 s duty cycle pulses (spark gap drivers input), corresponding to each shock wave generation.

3: The variable short-time delay (50 to 950 s) between the two succesive shock waves.

The diagram of the pulse generator circuit is shown in Fig. 5. The automatic-mode low frequency signal was obtained using $I C 1$ (XR2240) in a stable operation with time base period $T=(R V 1+R 1) C 1$ and final period $T O=64 T$. This was achieved using the $6^{\text {th }}$ bit of the internal binary counter as an output [11]. For $C=1.5 \mu \mathrm{F}, R 1=10 \mathrm{k} \Omega$ and $R v 1=0-$ $100 \mathrm{k} \Omega$, To ranges between 0.96 and $10.56 \mathrm{~s}$, i.e. a frequency from 0.095 to $1.04 \mathrm{~Hz}$. Pins 10 and 11 of the XR2240 are reset and trigger inputs activated with positive-going control pulses. The output of this time base (pin 6) provides the necessary rise time to activate the second time base obtained by means of a typical monostable configuration with the $/ C 2(S N 74127)$, where $T=\operatorname{Ln}(2)(15 \mathrm{k} \Omega)(4.7 \mathrm{nF})=48.87 \mu \mathrm{s}$ is the duty cycle for the first discharge pulse sent to spark 
gap driver 1. This was achieved by means of the led (in the opto-coupler module) supported by the $2 \mathrm{~N} 2222$ transistor array, whose input is connected to $/ C 2$ output (pin 6). Input of $/ C 2$ (pin 5) also is connected to the collector of transistor $B C 547$ operating as a switch to fire the second time base in manual mode, by means of the start pushbutton and the toggle selector in corresponding position.

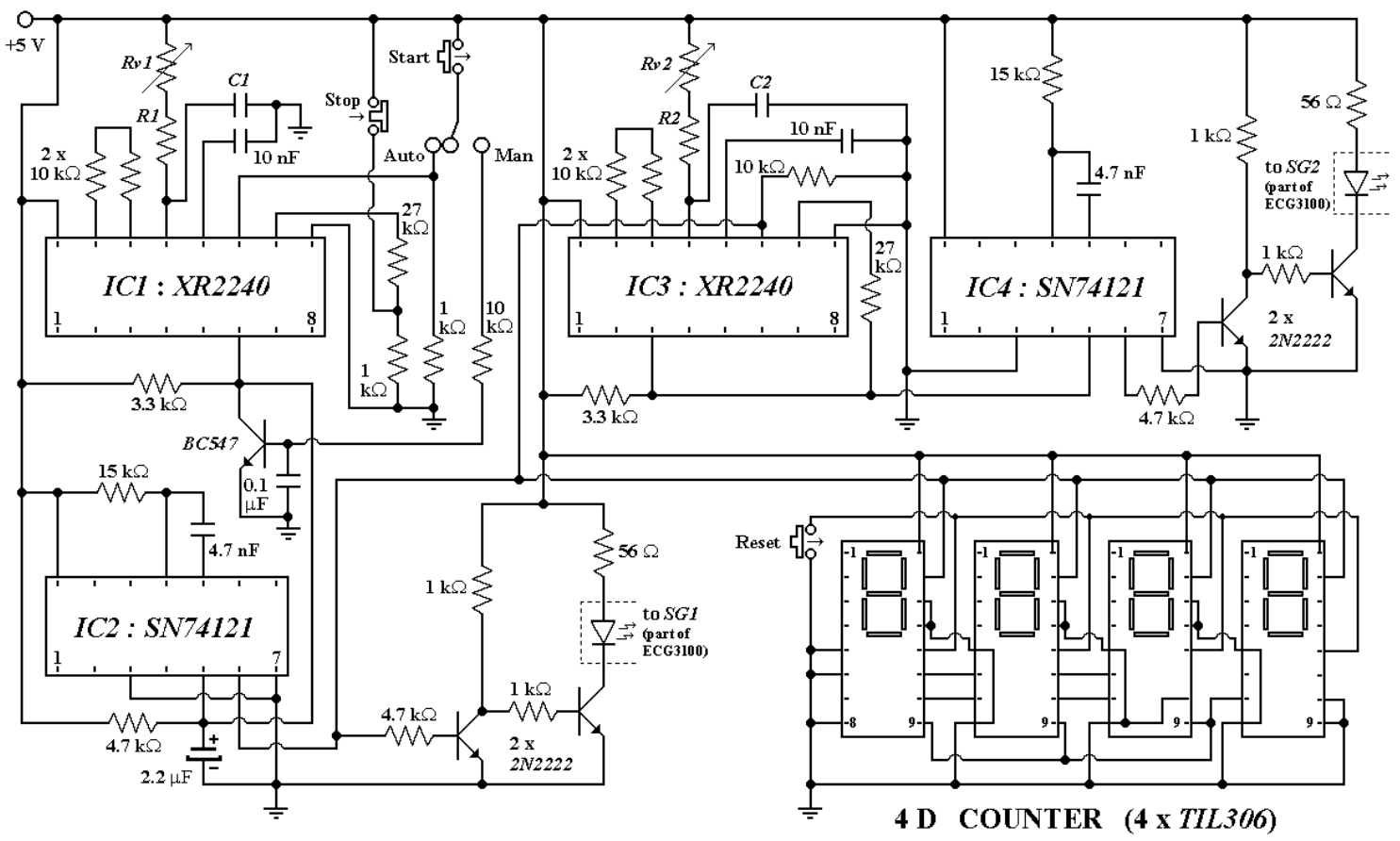

Figure 5. Diagram of the pulse generator

The third time base was obtained as the first one, but using the $X R 2240(/ C 3)$ in mono stable operation fired by IC2 output. Using the $3^{\text {ti }}$ bit of its internal binary counter as output and $C 2=12 \mathrm{nF}, R 2=1 \mathrm{k} \Omega, R v 2=0-20 \mathrm{k} \Omega$, this stage provides a $48-1008 \mu$ s delay interval. The delay may be varied with precision by adjusting the ten-turn potentiometer Rv2. After the selected time delay finishes, a positive-going pulse is generated at /C3 output (pin 3) which fires /C4 (in identical configuration to / $/(2)$, to provide the second discharge pulse for spark gap driver 2 using the above mentioned optical coupling. The digital counter was assembled with four T/L306 microcircuits in a typical configuration suggested by the manufacturer [12].

\section{EVALUATION AND RESULTS}

\subsection{Electronic instrumentation}

Before installing the novel device on the lithotripter shock wave generator, each spark gap driver was loaded in excess of its design specifications, using a Mazda model 92-4265, 18 inches, 30 watt gas-filled tube. These type of discharge lamp is used in photocopying machines. A set of 1000 tandem discharges were delivered to the gas-filled tube at a delay of $500 \mu \mathrm{s}$, a frequency of $2 / 3 \mathrm{~Hz}$ and a temperature of $18.2 \pm 0.2{ }^{\circ} \mathrm{C}$, registered using an Extech 445800 hygrothermometer. The delay between tandem discharges was observed on a Gould DSO-475 oscilloscope at a $50 \mu \mathrm{s}$ time scale, using a 1000:1 high-voltage probe (Schlumberger model 70-457E). No delay variation larger than $\pm 5 \mu \mathrm{s}$ could be detected. The process was repeated at five different temperatures $\left(10.0,12.3,15.0,22.1\right.$ and $\left.25.2^{\circ} \mathrm{C} \pm 0.2^{\circ} \mathrm{C}\right)$ with the same result. Finally, 9600 tandem discharges were delivered to the discharge lamp at a delay of $400 \mu \mathrm{s}$, and the same frequency of $2 / 3 \mathrm{~Hz}$. Temperature was allowed to vary between 15.4 and $17.9^{\circ} \mathrm{C} \pm 0.2^{\circ} \mathrm{C}$. During the whole process ( 4 hours) the delay was measured every 5 minutes. No variation larger than $\pm 5 \mu$ s was observed. 


\subsection{Tandem shock wave generation}

The system was arranged as shown in Fig. 3. The trigger and channel one of a digital oscilloscope (Tektronix Inc., Beaverton, OR, USA, model 2430A ) was connected to $T 1$ and $T 2$, respectively. Pressure variations at the focus $F$ of the shock wave generator were registered using a piezoelectric pressure transducer (Kistler Instruments AG, Winterthur, Switzerland, model 603B7) connected to a Kistler 5004 charge amplifier. Water level inside the test tank was set $10 \mathrm{~cm}$ above $F$. Figure 6 shows a typical graph observed on the oscilloscope at $0.5 \mathrm{~V} /$ div and $200 \mu \mathrm{s} /$ div using a $550 \mu$ delay. The spark gap high voltage discharge signals were registered on the screen at the preset delay. About $230 \mu \mathrm{s}$ after the oscilloscope was triggered, the first shock wave reached the hydrophone at $F$. This was the time needed for the pressure wave to travel from the piezoelectric crystal array to the hydrophone at a velocity of about $1500 \mathrm{~m} / \mathrm{s}$. About $550 \mu \mathrm{s}$ after firing the first spark gap, the signal of the second spark gap appeared on the screen. The second shock wave also was registered about $230 \mu \mathrm{s}$ after its generation.

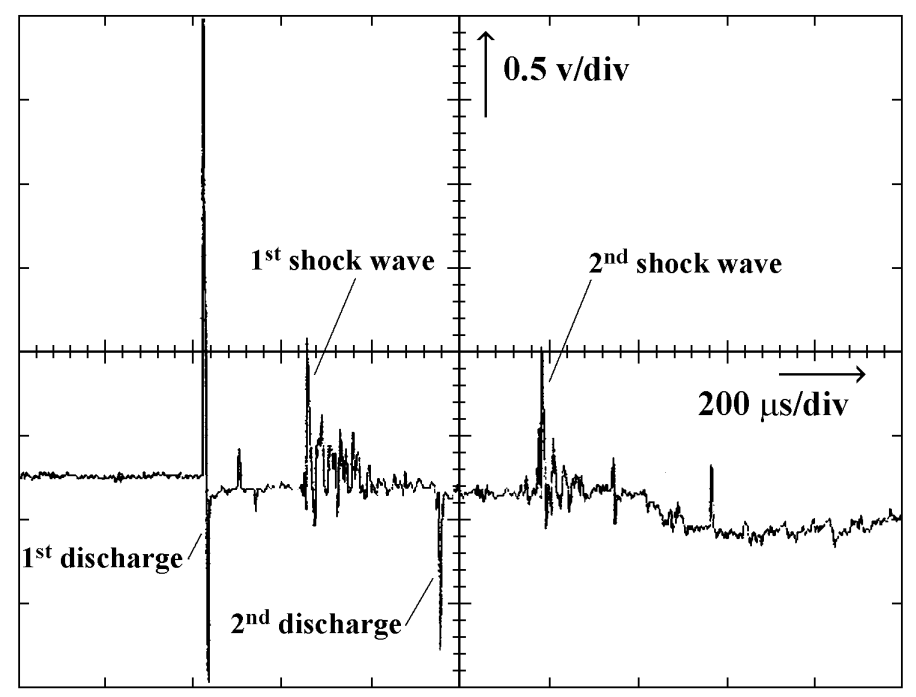

Figure 6. Pressure waveform obtained at the focus of the tandem shock wave generator at a delay of $550 \mu$ s between shock waves

In order to evaluate the fragmentation efficiency of model kidney stones at 11 different delays between tandem shock waves, a set of four $1.6 \pm 0.1 \mathrm{~g}$ spherical stone phantoms (diameter $=1.5 \pm 0.01 \mathrm{~cm}$ ), manufactured by High Medical Technologies in Kreuzlingen Switzerland (model AST 109), were placed one by one in a polyethylene bag at $F$ and exposed to 500 tandem shock waves for each delay. Delays were increased from 100 to $600 \mu$ s in steps of $50 \mu$ s. Before shock wave application, stone phantoms were saturated in water for 10 minutes. Shock wave exposed model kidney stones were strained through a $1 \times 1 \mathrm{~mm}$ nylon mesh. Stones and fragments were dried in an oven at $50{ }^{\circ} \mathrm{C}$ and weighed on a precision scale (Sartorius $\mathrm{GmbH}$, Göttingen, Germany, model 2842) with an accuracy of $\pm 10^{4} \mathrm{~g}$. Figure 7 shows the fragmentation efficiency defined as $F=100(\mathrm{Wi}-\mathrm{Wf}) / \mathrm{W}$, where $W i$ is the initial (intact) stone weight and $W f$ the final weight of the fragments. Maximum fragmentation efficiency was observed at $250 \mu s$. At delays above about $400 \mu$ s Fwas comparable to the efficiency obtained when exposing models to 1000 single shock waves using the standard system. 


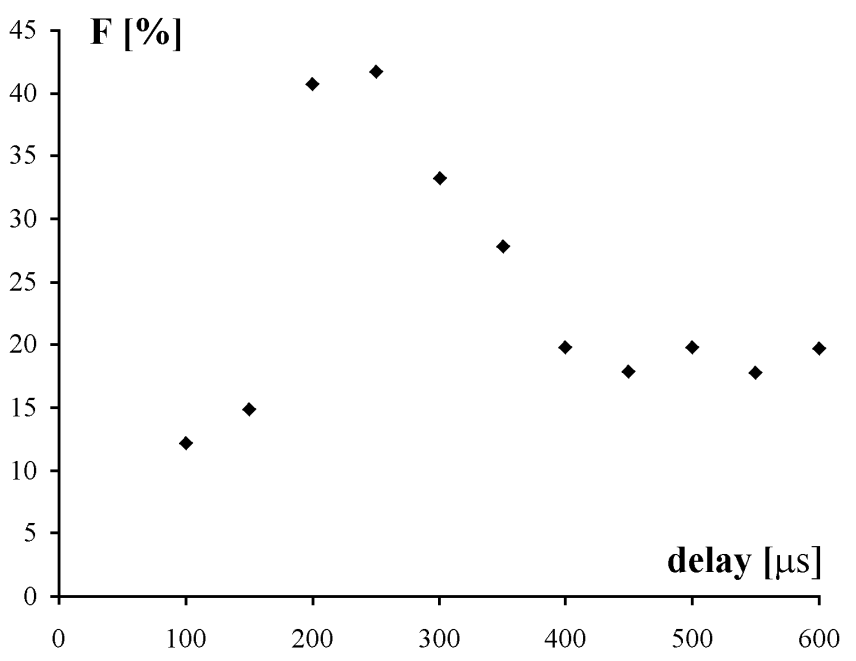

Figure 7. Fragmentation efficiency of spherical kidney stone phantoms exposed to 500 tandem shock waves generated at $7.5 \mathrm{kV}$ using different delays between first and second shock wave

\section{CONCLUSIONS}

Kidney stone fragmentation efficiency during ESWL depends on several factors such as shape, composition and location of the calculus, as well as number of shock waves, pressure profile, and administration frequency. Our results seem to indicate that cavitation-induced damage to model kidney stones can be enhanced using a piezoelectric tandem shock wave generator. The electric and electronic circuits described here could be installed in clinical lithotripters without changing the design of the device. Increased fragmentation efficiency of about 20\%, compared to the standard configuration, was obtained at a shock wave delay of $250 \mu \mathrm{s}$. These results are comparable to data obtained using bifocal reflectors for electrohydraulic shock wave generators [6]. Enhanced calculi fragmentation using the piezoelectric tandem shock wave generator is based on the fact that collapse of cavitation bubbles formed by the first shock wave can be intensified significantly if a second shock wave arrives at the bubbles during or shortly after their stable phase [13]. The main advantage of our system is that there is no need to manufacture a new hybrid reflector for every desired time delay between shock waves. Due to this, delays could be adjusted depending on the size, composition and location of the kidney stone. In vitro and in vivo experiments will be necessary to determine whether tandem shock wave application should be used clinically.

\section{ACKNOWLEDGEMENTS}

The authors would like to acknowledge technical assistance by Arturo Méndez, Edgar Méndez, Helmuth Busch and Mario Granizo. The Piezolith 2300 shock wave generator was donated to our univeristy by Dewimed S.A. de C.V.

\section{REFERENCES}

[1] Loske, A. M., Prieto, F. E. "Shock Waves in Medicine, Commented Bibliographical Data Base". Mexico City, CIC-UNAM, 1995.

[2] Loske, A. M., Prieo, F.E. "Fundamentos Técnicos de Litotripsia Extracorporal". México City: JGE Editores, 1999.

[3] Loske, A. M. "Applications of shock waves in medicine", in Handbook of Shock Waves, Ben-Dor, G., Elperin, T., Igra O., Lifshitz, A. (ed.). New York: Academic Press, 2001, Vol. 2, chapter XII.

[4] Crum, L. A. "Cavitation microjets as a contributory mechanism for renal calculi disintegration in ESWL." J. Urol. 1988; 140, pp, $1587-1590$.

[5] Lokhandwalla, M., Sturtevant, B. "Fracture mechanics model of stone comminution in ESWL and implications for tissue damage". Phys. Med. Biol. 2000, 45, pp, 1923 - 1949. 
[6] Prieto, F. E., Loske, A. M. "Bifocal reflector for electrohydraulic lithotripters". The Journal of Endourology, vol. 13, number 2, 1999, 65-75.

[7] Xi, X., Zhong, P. "Improvement of stone fragmentation during shock-wave lithotripsy using a combined EH/PEAA shock-wave generator - in vitro experiments". Ultrasound Med. Biol. 2000, 26, 457 - 467.

[8] Cady, W. "Piezoelectricity: An Introduction to the Theory and Applications of Electromechanical Phenomena in Crystals". New York. Dover Publications Inc., vol. I, 1964.

[9] The Power Semiconductor Data Book, Texas Instruments Inc., USA, 1971.

[10] TL Logic Data Book, Texas Instruments Inc., USA, 1988.

[11] Exar Databook, Exar Corp., USA, 1992.

[12] Optoelectronics Data Book, Texas Instruments Inc., USA, 1972.

[13] Zhong P., Cocks, F. H. Cioanta, I., Preminger, G. M. "Controlled, forced collapse of cavitation bubbles for improved stone fragmentation during shock wave lithotripsy". J. Urol. 1997, 158; 2323 - 2328.

Authors Biography

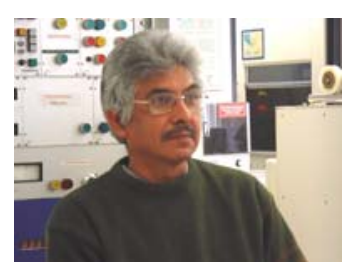

Francisco Fernández Escobar,

Was born in Acapulco city in 1953. He obtained a B.Sc. degree in Physics at the Facultad de Ciencias, UNAM (Faculty of Science of the UNAM) in Mexico City and completed his M.Sc. studies at the same university. As experimental physicist, he has worked at Universidad Nacional Autónoma de México (National Autonomous University of Mexico, UNAM), since 1976; first in the field of electronic scientific instrumentation at Facultad de Física (Science Faculty 1976 1986) and at Instituto de Física (Physics Institute 1986-2001); and recently in the field of shock waves experimentation at Centro de Física Aplicada y Tecnología Avanzada of the National Autonomous University of Mexico (The Center of Applied Physics and Advanced Technology, UNAM) in Juriquilla, Querétaro.

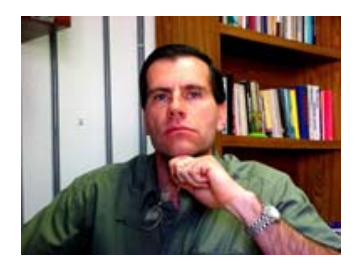

Achim Max Loske Mehling,

Was born in Mexico City in 1960. He completed a B.Sc. degree in Physics Engineering at the UI (Universidad Iberoamericana) in Mexico City, a M.Sc. degree in Physics at the Facultad de Ciencias, UNAM (Faculty of Science of the UNAM) in Mexico City, and a Ph.D. in Applied Physics at the Centro de Investigación Científica y de Educación Superior de Ensenada, Baja California, Mexico. His master and doctoral thesis involved experimentation of shock waves applied to medicine at the Instituto de Física, UNAM (Physics Institute of the UNAM) Achim Loske is Head of the Shock Wave Laboratory at the Centro de Física Aplicada y Tecnología Avanzada of the UNAM (Center of Applied Physics and Advanced Technology of the National Autonomous University of Mexico) in Juriquilla, Querétaro. He received the Gabino Barreda Medal in 1997 and is member of the Sistema Nacional de Investigadores (Nacional System of Research), the "Sociedad Mexicana para la Divulgación de la Ciencia y la Técnica", and the "Sociedad Mexicana de Instrumentación". 